\title{
Democracia e empoderamento no contexto da promoção da saúde: possibilidades e desafios apresentados ao Programa de Saúde da Família
}

I 'Poliana Cardoso Martins, '2Rosângela Minardi Mitre Cotta, ${ }^{3}$ Rodrigo Siqueira-Batista, ${ }^{4}$ Fábio Farias Mendes, ${ }^{5}$ Sylvia do Carmo Castro Franceschinni, ${ }^{6}$ Silvia Eloiza Priore,

${ }^{7}$ Glauce Dias I

Resumo: O Programa Saúde da Família (PSF) é visto como uma das principais estratégias de reorganização do SUS, redirecionando o modelo de atenção à saúde no Brasil, atuando com um novo padrão que valoriza as ações de promoção da saúde, prevenção das doenças e atenção curativa. No contexto da democracia em saúde, destaca-se a promoção da saúde como o processo no qual os indivíduos são capacitados para ter maior controle sobre a própria saúde, reconhecendo a importância do poder e do controle sobre os determinantes da saúde, utilizando-se de estratégias que visem a empoderar os sujeitos, aumentando sua participação na modificação dos elementos relevantes à saúde. Este artigo visa a realizar uma reflexão crítica sobre a importância do PSF para a promoção e estímulo ao empoderamento/libertação da população, vislumbrando sua participação mais ativa na tomada de decisão na área da saúde.

> Palavras-chave: participação comunitária; educação em saúde; Programa de Saúde da Família; sistema de saúde.
1 Professora assistente, Instituto Multidisciplinar de Saúde, Universidade Federal da Bahia, Mestre em Ciências da Nutrição pela Universidade Federal de Viçosa.

2 Professora adjunta, Departamento de Nutrição e Saúde, Universidade Federal de Viçosa; Doutora em Saúde Pública pela Universidade de Valência, Espanha; orientadora/ coordenadora. Endereço eletrônico: rmmitre@ufv.br

3 Professor, Centro Federal de Educação Tecnológica de Química de Nilópolis-RJ, Fundação Educacional da Serra dos Órgãos; Doutor em Ciências pela Fundação Oswaldo Cruz.

4 Professor adjunto, Departamento de Artes e Humanidades, Universidade Federal de Viçosa; Doutor em Ciência Política pelo IUPERJ

5 Professora adjunta, Departamento de Nutrição e Saúde, Universidade Federal de Viçosa; Doutora em Ciências da Saúde pela Escola Paulista de Medicina, Universidade de São Paulo.

6 Professora adjunta, Departamento de Nutrição e Saúde, Universidade Federal de Viçosa; Doutora em Ciências da Saúde pela Escola Paulista de Medicina, Universidade de São Paulo.

7 Mestre em Ciências da Nutrição pela Universidade Federal de Viçosa. 
O pensamento sobre promoção da saúde no Brasil está associado ao Sistema Único de Saúde (SUS) e ao enfretamento de uma realidade de iniquidades históricas, que colocam desafios cotidianos não só ao setor saúde, mas a todos aqueles que constroem políticas públicas. Podem-se observar algumas ideias e posições da promoção da saúde nas políticas sanitárias brasileiras, apresentando-se em todos os níveis de complexidade da gestão e da atenção.

Nota-se o incentivo ao deslocamento do olhar e da escuta dos profissionais de saúde, da doença para os sujeitos em sua potência de criação da própria vida, objetivando, durante o processo do cuidado à saúde, a produção de coeficientes crescentes de autonomia (CAMPOS; BARROS; CASTRO, 2004). Palavra de origem grega - aplicada, na Antiguidade, à condição de autogoverno das póleis (cidadesestado) e reorientada à situação do indivíduo na modernidade (KANT, 1960) autonomia é aqui entendida no sentido de autodeterminação da pessoa, em princípio a mais qualificada para avaliar e decidir o rumo de sua vida, desde que possa ser considerada cognitiva e moralmente competente (SCHRAMM, 2001). A autonomia - lado a lado com a justiça - é um conceito-chave no debate éticopolítco hodierno, especialmente na construção das sociedades democráticas, laicas e plurais contemporâneas (BORNHEIM, 2002; SCHRAMM, 1998).

No Brasil, como em vários países da América Latina, as desigualdades socioeconômicas acabam por prevalecer e a participação da promoção da saúde no desenvolvimento social e econômico do país é pequena. Apesar dessa realidade, o ideário da promoção da saúde influenciou diretamente a elaboração do arcabouço teórico do modelo de Vigilância à Saúde, fazendo-se presente junto ao projeto de reestruturação da rede básica de saúde, sob o manto do Programa de Saúde da Família - PSF (CARVALHO, 2004; SOUZA; GRUNDY, 2004).

Algumas características do PSF favorecem a integração entre a comunidade e as equipes (CREVELIM; PEDUZZI, 2005). As atividades desenvolvidas pelas equipes podem levar a um maior envolvimento e articulação com a comunidade, induzindo o reconhecimento das capacidades criativas, propositivas e gerenciais das camadas populares que podem ser demonstradas continuamente, através de inúmeros movimentos e iniciativas próprias, que estimulem democraticamente a participação popular, remetendo ao conceito de empoderamento, que constitui um eixo central da promoção da saúde (OLIVEIRA; GUSMÃO, 2004; SOUZA; GRUNDY, 2004). 
Empoderamento - termo traduzido diretamente do inglês empowerment-pode ser entendido como a ampliação das possibilidades de controle, por um sujeito ou uma população, dos aspectos significativos relacionados à sua própria existência, de acordo com a concepção do economista indiano Amartya Kumar Sen (SEN, 2001; 2002). Por outro lado, o conceito de "libertação", do pensador brasileiro Paulo Freire (FREIRE, 2003; 2004), parece referir-se ao mesmo fenômeno expresso na palavra "empowerment", além de constituir excelente alternativa para a redução dos aspectos de inclusão social e resgate da cidadania a uma mera questão de poder (GARRAFA, 2005). Em decorrência disto, utilizar-se-á o binômio empoderamento/libertação como substituto de "empowerment".

Entendendo que a promoção da saúde se apoia na democratização das informaçôes e num trabalho conjunto de toda a sociedade para a superação dos problemas, envolvendo a descentralização do poder e as ações multidisciplinares e intersetoriais, além da participação da população na formulação de políticas públicas e nos processos de decisões. Onde a criação de espaços para o exercício da cidadania é um elemento essencial para o empoderamento/libertação da população, faz-se necessário desenvolver processos participativos que promovam o desenvolvimento da capacidade dos indivíduos controlarem situações, a partir da conscientização dos determinantes dos problemas ou da formação do pensamento crítico (BYDLOWSKI; WESTPHAL; PEREIRA, 2004) e o PSF pode ser pensado como um lócus favorável para este exercício.

O presente estudo tem como objetivo apresentar uma reflexão teórica sobre as possibilidades e desafios apresentados ao PSF para exercer seu papel como um instrumento capaz de promover e estimular o empoderamento/libertação da população, possibilitando a consolidação do princípio democrático de participação popular no SUS.

\section{O Programa de Saúde da Família: trajetória, diretrizes e envolvimento da população na atenção à saúde}

O PSF tem como propósito a superação da visão fragmentada do ser humano para uma compreensão integral na dimensão individual, familiar e coletiva, ou seja, o resgate da prática generalista, onde a compreensão do processo saúde-doença a que estão expostos os indivíduos passa a ser pensado de forma mais ampla, segundo a realidade local, comunitária e familiar (OLIVEIRA; GUSMÃO, 2004). Nesse 
sentido, concebido inicialmente como um programa de saúde, é considerado pelo Ministério da Saúde como "uma estratégia estruturante dos sistemas municipais de saúde visando à reorientação do modelo de atenção e uma nova dinâmica da organização dos serviços e ações de saúde" (BRASIL, 2008).

O PSF é colocado como uma alternativa para a reorganização de sistemas de saúde, segundo os princípios do SUS. Busca a incorporação da promoção da saúde, do trabalho interdisciplinar e multiprofissional, do envolvimento comunitário e de uma lógica de responsabilização entre os diversos atores sociais envolvidos no processo de construção do sistema sanitário (BECKER, 2001). Tem como premissa a territorialização, que permite a demarcação de um espaço concreto de trabalho da equipe, onde o núcleo familiar é visto como base de sua atuação. Possibilita, assim, a compreensão da dinâmica do núcleo familiar, entendendo suas relações na sociedade, inclusive o modo social de produção, avaliando quais determinantes sociais contribuem para o desenvolvimento do processo de saúde na comunidade; atua como orientador das políticas intersetoriais, facilitando a compreensão das estruturas que precisam ser modificadas com vistas ao bem-estar da comunidade.

Outro ponto importante a se destacar é a capacidade de conhecer a realidade epidemiológica, utilizar as ferramentas informatizadas já disponíveis e traduzir as informações para uma linguagem acessível à sua comunidade, possibilitando a construção de metas e pactos visando a uma vida com saúde para seus membros, com avaliação dos impactos produzidos em tempos determinados (OLIVEIRA; GUSMÃO, 2004). Diante dessa realidade, o PSF é capaz de ser um importante mobilizador das forças sociais que nesse espaço atuam, facultando a interação com o governo local na busca de soluções para os seus problemas (BRASIL, 1999).

A participação popular, nesse contexto, é extremamente importante, pois permite aos cidadãos exercerem um papel real sobre a organização do sistema local de saúde. De fato, o PSF deve ser entendido no contexto da participação social, através da lógica da vigilância à saúde, representada pela concepção da saúde centrada na promoção da qualidade de vida e no usuário (MENDES, 2006) e através do modelo usuário-centrado, que coloca o cidadão no centro da atenção e do cuidado em saúde (AYRES, 2004). As bases legais do direito à saúde são postas nessa nova conjuntura, cabendo destaque ao direito de cidadania, cuja consequência é a valorização da participação popular nas decisões sobre a política de saúde, por 
meio das relações que são estabelecidas entre os profissionais das equipes de saúde da família e a comunidade (OLIVEIRA; GUSMÃO, 2004).

Apesar destas características, alguns estudos realizados em equipes do PSF têm demonstrado a ausência do usuário como protagonista de seu próprio viver e da produção de seu cuidado com a equipe, visto que muitas vezes a própria equipe o coloca fora do âmbito das decisóes que lhe dizem respeito (CREVELIM; PEDUZZI, 2005; MATUMOTO, 2003), numa clara desconsideração de sua autonomia. Diante dessa realidade, a participação social deve ser entendida como fato político, porque representa o exercício de uma capacidade organizativa concreta da população, tendo em vista o controle sobre atividades públicas. É uma ativação da sociedade civil com a presença da população na arena política em defesa de seus interesses (MENDES, 2006). Cabe ao Estado formar ${ }^{1}$ a população, favorecendo sua emancipação política; neste aspecto, o PSF pode ser utilizado como um substantivo instrumento, haja vista seus princípios e diretrizes. Desde esta perspectiva, é necessário restabelecer a interação dialética entre Estado e sociedade civil, e não apenas uma dicotomia, porque um é produto do outro, e as pessoas e os grupos se entrelaçam em ambos, sendo a relação de controle democrático (DEMO, 2003).

Como forma de ilustração, pode-se destacar o município de Vitória da Conquista (BA), onde o Estado estimula o controle social, partindo do desejo de educar a população e, ao mesmo tempo, se educar, utilizando para tal tarefa as equipes de saúde da família. São geradas, assim, as possibilidades para que o governo e a população possam construir juntos uma cidade verdadeiramente democrática e menos desigual, incentivando ainda a prevalência do respeito e da garantia dos direitos socais conquistados, que muitas vezes não são exercidos pela população. A partir desta forma democrática de gestão, o município vem alcançando resultados positivos na qualidade dos serviços prestados à comunidade. A política de saúde de Vitória da Conquista é um exemplo de política pública exitosa, devido ao esforço coletivo empreendido pelos profissionais, pelos gestores e pelos usuários, que têm como prioridade a luta pelo cumprimento dos princípios e diretrizes do SUS (OLIVEIRA; GUSMÃO, 2004).

O Ministério da Saúde, em parceria com a Organização Pan-Americana da Saúde (OPAS), vem articulando uma proposta de atuação da equipe de saúde da família com foco na organização do cuidado com base nos problemas. Assinala a 
necessidade de introduzir novas formas de poder, tanto para os membros da equipe como para algumas lideranças da comunidade, que se transformarão em interlocutores privilegiados no processo de tomada de decisão (OLIVEIRA; GUSMÃO, 2004). Assim, a dinâmica de inclusão social deve pressupor não somente o direito de acesso aos equipamentos públicos, mas o reconhecimento das capacidades criativas, propositivas e gerenciais das camadas populares que podem ser demonstradas continuamente, através de movimentos e iniciativas próprios, que estimulam a participação popular (BYDLOWSKI; WESTPHAL, PEREIRA, 2004).

Nesse sentido, entende-se que o compromisso ético-político do próprio SUS é o compromisso com a promoção da saúde, que junto à integralidade e à gestão participativa coloca os sujeitos (usuários e profissionais de saúde) como protagonistas na organização do processo produtivo em saúde. Estabelece, assim, modos de atenção e gestão que operem na indissociabilidade entre a clínica e a promoção, e entre as necessidades sociais e as ações do Estado. Torna-se importante o diálogo constante com os movimentos sociais, criando formas de articulação mais permanentes e sustentáveis, na medida em que se multiplicam as possibilidades de enfrentamento dos problemas de saúde pública e qualificam-se cada vez mais as ações no SUS, para a redução da vulnerabilidade e para a melhoria da qualidade de vida da população. Essa postura ético-teórico-política se expressa no compromisso em reorganizar os serviços de saúde e preparar os profissionais de saúde que ali atuam para incluírem a população na construção e na gestão de seus projetos de saúde e processos de trabalho (CAMPOS; BARROS; CASTRO, 2004). É precisamente neste horizonte que se inscreve o debate atual sobre o binômio empoderamento/libertação, como será discutido a seguir.

\section{O Programa de Saúde da Família e o empoderamento/ libertação da população}

O PSF, entendido dentro da lógica da vigilância à saúde, representa a saúde centrada no usuário na concepção de qualidade de vida e da promoção da saúde (FRANCO; BUENO; MERHY, 1999; OLIVEIRA; GUSMÃO, 2004; MENDES, 2006).

A promoção da saúde é vista como uma estratégia mediadora entre o ambiente e a sociedade, visando a aumentar a participação dos sujeitos e das coletividades na modificação dos determinantes do processo saúde-doença, como emprego, renda, educação, cultura, lazer e hábitos de vida, onde o Estado tem a 
responsabilidade de reduzir as diferenças, assegurando a igualdade de oportunidades e promovendo meios que permitam a todos desenvolverem um melhor controle sobre sua saúde (AYRES, 2004).

A partir dessas perspectivas, destaca-se a importância estratégica do conceito de empoderamento (empowerment), definido como o processo através do qual as pessoas ou as comunidades adquirem maior controle sobre as decisões e ações que afetam sua saúde (WHO, 1998), ampliando as possibilidades de controle dos aspectos significativos relacionados à sua própria existência (SEN, 2001; 2002), o qual está em íntima interseção com a ideia de libertação trabalhada por Freire (2003; 2004). Amartya Sen expressa empoderamento para aquilo que Paulo Freire chama de libertação daqueles cidadãos que logram sua inclusão social; entretanto, este traz uma concepção mais ampla e generosa do cidadão que se liberta da situação de exclusão por meio da educação (GARRAFA, 2005).

O conceito de empoderamento é complexo e toma emprestadas noções de distintos campos do conhecimento, tendo suas raízes nas lutas pelos direitos civis, no movimento feminista e na ideologia de "ação social" da metade do século XX. Também é influenciado pelos movimentos de autoajuda dos anos 70, da psicologia comunitária nos anos 80 , e na década de 90 recebe influência dos movimentos que buscam afirmar o direito à cidadania (CARVALHO, 2004). O empoderamento e a participação social são conceitos que fazem parte do campo de ação da promoção da saúde, sendo a efetiva e concreta participação social estabelecida como objetivo essencial da promoção de saúde (WHO, 1984).

$\mathrm{Na}$ Carta de Ottawa (1986), esse campo de ação é definido como o processo de desenvolvimento na comunidade, da capacidade de controle e de habilidades para gerar mudanças nos condicionantes sociais da saúde, através da mobilização coletiva, onde o desenvolvimento da comunidade se baseia nos recursos humanos e materiais com que conta a comunidade para estimular a independência e o apoio social. Tanto na Carta de Ottawa como na Declaração de Adelaide (1988), a ação comunitária é o ponto central da promoção de políticas públicas para a saúde, pelas quais a comunidade busca a posse e o controle de seus próprios esforços e destinos (OPAS, 2006).

Nessa mesma direção, a Declaração de Sundsvall (1991) propõe reforçar a criação de ambientes saudáveis através de ações comunitárias de maior controle sobre a saúde e o ambiente, e maior participação nos processos de tomada de 
decisões. Por fim, destaca-se a Declaração de Bogotá (1992), por sugerir que a ação comunitária é capaz de fortalecer a capacidade da população para participar das decisões que afetam sua vida e optar por modos de vida saudáveis através do diálogo de diferentes saberes (OPAS, 2006).

O conceito de empoderamento/libertação, presente implícita ou explicitamente nestas cartas, corporifica a razão de ser da promoção da saúde enquanto um processo que procura possibilitar que os indivíduos e coletivos aumentem o controle sobre os determinantes de saúde, para conseguirem uma melhor saúde e qualidade de vida (CZERSNIA; FREITAS, 2003). Nesta perspectiva, o cidadão se situa no centro do modelo de prestação de cuidados de saúde, tendo como questão central o exercício positivo desse poder na construção de uma cidadania participativa, não se resumindo somente à obtenção de poder, de direitos e sua defesa. Este exercício implica criar as condições para que o cidadão tenha uma ativa contribuição para o empoderamento/libertação individual, isto é, para tomar decisões e exercer controle sobre sua vida pessoal; e o empoderamento/libertação coletivo, onde os indivíduos atuam coletivamente, a fim de conseguir maior influência e controle dos determinantes de saúde e qualidade de vida da sua comunidade (TEIXEIRA, 2002).

O empoderamento/libertação da população, através da difusão ampla das evidências das relações entre saúde e seus pré-requisitos, assim como da construção de mecanismos de atuação eficientes, é central na estratégia da promoção da saúde. Com efeito, é capaz de levar a uma nova distribuição de deveres e direitos entre o Estado e a sociedade, redimensionando a questão da participação, a qual passa a ser entendida como pré-requisito institucional e político para a definição da "saúde que queremos”. Não é apenas uma circunstância desejável, mas uma condição indispensável para a viabilidade e efetividade das políticas públicas (BUSS, 2000).

Esta abordagem trabalha a noção de poder como um recurso distribuído de forma desigual na sociedade (FOUCAULT, 1996) e uma questão geradora de conflito, na qual convivem visōes potencialmente criativas e transformadoras com elementos de conservação do status quo. Parte do paradigma de que a sociedade é constituída por diferentes grupos de interesse, com níveis diferenciados de poder e de controle sobre os recursos, fazendo com que processos de empoderamento levem à redistribuição de poder e à inclusão social/libertação (CARVALHO, 2004; FREIRE, 2004). 
Estratégias de empoderamento/libertação da comunidade supõem, entre outras iniciativas, a educação para a cidadania, a socialização de informações, o envolvimento na tomada de decisóes dentro de um processo de diagnóstico, do planejamento e de execução de projetos e ou iniciativas sociais.

Neste processo de empoderamento/libertação, observa-se a presença de fatores situados em distintas esferas da vida social. No plano individual, estão a autoconfiança e autoestima; na mesosfera social, observam-se estruturas de mediação, na qual membros de um coletivo compartilham conhecimentos e ampliam sua consciência crítica; e na macroesfera, há estruturas sociais como o Estado e a macroeconomia (CARVALHO, 2004; GONH, 2004). Ao se pensar no PSF como uma estratégia de reorganização da assistência sanitária, em que a atenção primária é o foco central da atenção, e como um espaço onde ações de promoção, prevenção e cura são realizadas no âmbito individual e coletivo, podemos inferir que esta estratégia se insere em todas as esferas sociais, podendo ser interpretada como um lócus situado num novo perfil de atuação da sociedade civil organizada na gestão do sistema sanitário.

O PSF deve assumir sua função primordial no estímulo ao empoderamento/ libertação comunitário, uma vez que este pode possibilitar aos indivíduos e à coletividade o desenvolvimento de competências para participar da vida em sociedade, incluindo habilidades e pensamentos reflexivos (FREIRE; BETTO, 1985; LABRA, 2002). Este pensamento é reforçado na obra de Freire e Betto (1985, p. 14), como pode ser retratado por essa passagem:

[...] uma educação humanizada é o caminho pelo qual homens e mulheres podem se tornar conscientes da sua presença no mundo. A maneira como atuam e pensam quando desenvolvem todas as suas capacidades, tomando em consideração as suas necessidades, mas também as necessidades e aspirações dos outros.

Ao assumir a mudança no paradigma assistencial, passando de um eixo curativo para o preventivo, da ação monossetorial para a intersetorial, da exclusão para a universalidade, o PSF se torna um instrumento-chave para o empoderamento/ libertação da população. Esse programa deve detectar e sobretudo promover acontecimentos sociopolíticos que possam afetar a consciência social ou sanitária de grupos na comunidade, construindo condições para viabilizar a inclusão das bases da sociedade civil nos processos decisórios, seja por meio do fortalecimento dos Conselhos Municipais de Saúde, ou das instituições e segmentos sociais que 
possam exercer um controle social efetivo, garantindo a participação tanto na análise dos problemas de saúde, quanto na definição de intervenções. Estas seriam as prerrogativas para a construção de viabilidade social das mudanças no setor saúde (TRAD; BASTOS, 1998).

É interessante ressaltar a importância do desenvolvimento de práticas democráticas no processo de trabalho das equipes de saúde. A participação não é um conteúdo que se possa transmitir, tampouco uma destreza que se possa adquirir pelo mero treinamento, mas uma mentalidade e um comportamento a ser construído pela reflexão crítica e pelo amadurecimento do cidadão. Isso foi demonstrado desde tempos imemoriais, pelos gregos da pólis (ARISTÓTELES, 2000; PLATÃO, 1987), no processo de formação do homem, paideia, fundamental à atividade ético-política (JAEGER, 1995). A participação é uma vivência coletiva e não individual, de modo que somente se pode aprender na práxis grupal e só se aprende a participar, participando (BORDENAVE, 1983).

Segundo Crevelim e Peduzzi (2005), os limites para o processo de participação não se dão apenas por falta de infraestrutura e recursos, mas pela falta de uma cultura de participação, uma cultura cívica, assim como uma falta de vontade política para que a cidadania de fato seja exercida. Para que se fomente a participação social, é essencial a acumulação de experiências bem-sucedidas de união e cooperação entre os cidadãos e o Estado, que reforcem condutas de confiança recíproca.

Como processo social, a participação tem que ser gestada e amadurecida. É válido ressaltar a falta de tradição do nosso povo em movimentos sociais e no exercício da cidadania (SIQUEIRA-BATISTA, 2005). Para se chegar à participação nas definições e decisões sociais, não se pode deixar de considerar outros pressupostos da existência humana, como a garantia de condições adequadas de moradia, alimentação, educação, que em muitos casos são a principal preocupação da população, impedindo assim que esta se preocupe em participar ativamente da vida pública local (LABRA, 2002; SEN, 2001).

É necessário entender que a participação social não se resume à ação de compartilhar os espaços dos conselhos e outras instâncias da esfera pública. Para que se obtenha a participação, é primordial que se desenvolva uma cultura cívica aqui, uma vez mais, vale lembrar o exemplo dos gregos (JAEGER, 1995) -, a qual surge de estruturas participativas organizadas autonomamente na sociedade civil. Este trabalho na base da sociedade é fundamental para alimentar e fortalecer o 
controle social (GONH, 2004), apoiando as pessoas a realizarem suas próprias análises, para que tomem decisões que considerem corretas, desenvolvendo consciência crítica e a capacidade de intervir sobre a realidade, removendo as barreiras que limitam a vida em sociedade (CARVALHO, 2004).

$\mathrm{O}$ mais adequado para garantir o envolvimento e a participação da população nos programas de saúde é que estes sejam elaborados e aplicados juntamente com a população, e não impostos a ela, exercendo assim um processo de diálogo e negociação cuja situação deve ir mudando com propostas e programas desenhados pela população e executados pelo Estado. Esse processo de participação aumenta o sentido de responsabilidade, que significa consciência e cumprimento de deveres e direitos (BRICEÑO-LEON, 1998).

Dentro desse contexto, impõe-se a necessidade de refletir sobre como se apresenta o PSF no município, tanto do ponto de vista da população, como das particularidades do sistema, principalmente no que tange à organização dos serviços. A interação desses dois aspectos permite delinear a importância de fatores como: (1) necessidade e demanda da população aos serviços; (2) acesso aos recursos e disponibilidade dos serviços; (3) quantidade e qualidade da atenção; (4) resolubilidade; (5) relação custo-benefício; e (6) participação popular na construção do sistema de saúde de seu município.

\section{Considerações finais}

Diante desta realidade, é notório o papel que deve ser ocupado pelo PSF como um lócus favorável para o exercício da democracia e fortalecimento da promoção da saúde no Brasil. A participação popular, neste contexto, deve ser vislumbrada diante da possibilidade de os cidadãos exercerem o papel de protagonistas na construção e organização do sistema local de saúde. Entende-se que a participação não é um conteúdo que se possa transmitir, tampouco uma destreza que se possa adquirir pelo mero treinamento, mas uma atitude e um comportamento a ser construído pela reflexão crítica e pelo amadurecimento do cidadão, sendo, portanto, imprescindível a consolidação de práticas democráticas no processo de trabalho das equipes de saúde.

O trabalho cotidiano das equipes de saúde da família deve almejar a construção de possibilidades efetivas que insiram a população como participante ativa do processo de construção de um projeto assistencial comum. A equipe deve deixarse interagir com a comunidade, sendo reconhecida como integrante da mesma e 
como facilitadora da melhoria das condições de vida, com consequente geração de melhores condições de saúde.

Apesar de algumas evidências apontarem para a ausência do usuário como protagonista de seu próprio viver e da produção de seu cuidado em parceria com as equipes de saúde da família, deve-se reassumir o compromisso ético-político do próprio SUS com a gestão participativa, que coloca os sujeitos (usuários e profissionais de saúde) como responsáveis pela construção da organização do processo produtivo em saúde.

Tendo como referência o compromisso da promoção da saúde com a produção de sujeitos reflexivos autônomos e socialmente solidários, a viabilização deste compromisso passa pela criação de espaços e práticas democráticas no campo da saúde. A busca constante por espaços que valorizem a participação da comunidade e o encontro dos profissionais e usuários do SUS, atuando como parceiros na luta pela garantia dos direitos da cidadania, é a pedra de toque da autonomia. Desta forma, é necessário valorizar o PSF como um lócus favorável para o empoderamento/ libertação, não só da população, mas dos gestores e profissionais da área da saúde, contribuindo para o aumento da capacidade reflexiva e de participação na vida política. E isso é possível, desde que exista motivação, compromisso e vontade por parte de todos os protagonistas do SUS.

\section{Referências}

ARISTÓTELES. Constituição de Atenas. São Paulo: Nova Cultural, 2000.

AYRES, José R. C. M. Cuidado e reconstrução das práticas de saúde. Interface: Comunicação, Saúde e Comunicação. Botucatu, v. 8, n. 14, p. 73-92, set. 2003-fev. 2004.

BECKER, D. No seio da família: amamentação e promoção da saúde no Programa de Saúde da Família. 2001. Dissertação (Mestrado em Saúde Pública) - Escola Nacional de Saúde Pública, Fundação Oswaldo Cruz, Rio de Janeiro, 2001. 117p.

BORDENAVE, Juan E. D. O que éparticipação? São Paulo: Brasiliense; 1983. 87p.

BORNHEIM, Gerd A. As medidas da liberdade. In: NOVAES, A. (Org.). O avesso da liberdade. São Paulo: Companhia das Letras, 2002. p. 41-57.

BRASIL. Ministério da Saúde. Departamento de Atenção Básica. Disponível em <http:// dtr2004.saude.gov.br/dab/abnumeros.php\#numeros>. Acesso em: 24 jan. 2008.

. Secretaria de Assistência à Saúde. Manual de Organização para a Atenção Básica. Brasília:

Ministério da Saúde, 1999. 
BRICEÑO-LEON, Roberto. El contexto político de la participatión comunitária em América

Latina. Cad. Saúde Pública. Rio de Janeiro, v. 14, n. 2, p. 141-147, 1998.

BUSS, Paulo M. Promoção da saúde e qualidade de vida. Ciência \&s Saúde Coletiva. Rio de Janeiro, v. 5, n. 1, p. 163-177, 2000.

BYDLOWSKI, Cynthia R.; WESTPHAL, Márcia F.; PEREIRA, Isabel M. T. B. Promoção da saúde. Por que sim e por que ainda não! Saúde e Sociedade. São Paulo, v. 13, n. 1, p. 14-24, 2004. CAMPOS, Gastão W.; BARROS, Regina B.; CASTRO, Adriana M. Avaliação de política nacional de promoção da saúde. Ciência \& Saúde Coletiva. Rio de Janeiro, v. 9, n. 3, p. 745-749, 2004.

CARVALHO, Sérgio R. Os múltiplos sentidos da categoria “empowerment” no projeto de Promoção da Saúde. Cad. Saúde Pública. Rio de Janeiro, v. 20, n.4, p. 1.088-1.095, 2004.

CREVELIM, Maria A.; PEDUZZI, Marina. A participação da comunidade na equipe de saúde da família: é possível estabelecer um projeto comum entre trabalhadores e usuários? Ciência e Saúde Coletiva. Rio de Janeiro, v. 10, n. 2, p. 323-331, 2005.

CZERSNIA, Dina; FREITAS, Carlos M. Promoção da saúde: conceitos, reflexões, tendências. Rio de Janeiro: Fiocruz, 2003. 174p.

DEMO, Pedro. Política social, educação e cidadania. São Paulo: Papirus, 2003. 124p.

FOUCAULT, Michel. Microfísica do poder. Rio de Janeiro: Graal, 1996. 295p.

FRANCO, Túlio B.; BUENO, Wanderlei S.; MERHY Emerson E. O acolhimento e os processos de trabalho em saúde: o caso de Betim, Minas Gerais, Brasil. Cad. de Saúde Pública. Rio de Janeiro, v. 15 , n. 2, p. 345-353, 1999.

FREIRE, Paulo. Pedagogia da autonomia. Saberes necessários à prática educativa. São Paulo: Paz e Terra, 2003. 148p.

. Pedagogia do oprimido. São Paulo: Paz e Terra, 2004. 213p.

FREIRE, Paulo; BETTO, Frei. Essa escola chamada vida. São Paulo: Ática, 1985. 96p.

GARRAFA, Volnei. A inclusão social no contexto da bioética. In: CONGRESSO NACIONAL DA REDE UNIDA, 6. Painel "Bioética: inclusão e justiça social”. Anais... Belo Horizonte, 2005.

GONH, Maria da G. Empoderamento e participação da comunidade em políticas sociais. Saúde e Sociedade, v. 13, n. 2, p. 20-31, 2004.

JAEGER, Werner. Paideia: a formação do homem grego. São Paulo: Martins Fontes, 1995. 1440p. KANT, Immanuel. Fundamentação da Metafísica dos Costumes. Lisboa: Edições 70, 1960. 120p. LABRA, Maria E. Capital social y consejos de salud em Brasil. Um circulo virtuoso? Cad. Saúde Pública. Rio de Janeiro, v. 18, p. 47-55, 2002. 
MATUMOTO, Silvia. Encontros e desencontros entre trabalhadores e usuários na saúde em transformação: um ensaio cartográfico do acolhimento. 2003. Tese (Doutorado em Enfermagem) - Escola de Enfermagem de Ribeirão Preto, Universidade de São Paulo, Ribeirão Preto, 2003.

MENDES, Eugenio V. Uma Agenda para a Saúde. São Paulo: Hucitec, 2006. 304p.

OLIVEIRA, Jussiara B.; GUSMÃO, Stael C. A experiência de saúde da família no estímulo à participação social no município de Vitória da Conquista - BA. In: SECLEN-PALACIN, Juan; FERNANDES, Afra S. Experiências e desafios da atenção básica e saúde familiar: caso Brasil. Brasília: Organização Pan-Americana da Saúde, 2004. p. 63-76.

ORGANIZAÇÃO PAN-AMERICANA DA SAÚDE. Marco conceitual. Documentos que norteiam a promoção da saúde. Disponível em: <http://www.opas.org.br/coletiva/carta.cfm?idcarta=15>. Acesso em: 25 mar. 2006.

PLATÃO. A República. Introdução, tradução e notas de Maria Helena da Rocha Pereira. Lisboa: Fundação Calouste Gulbenkian, 1987.

SCHRAMM, Fermin R. ¿Por qué la definición de muerte no sirve para legitimar moralmente la eutanasia y el suicidio asistido? Perspectivas Bioéticas. Buenos Aires, v.6, n.11, p. 43-54, 2001.

. A autonomia difícil. Bioética. Brasilia, v.6, n.1, p. 27-37, 1998.

SEN, Amartya K. ¿Por quéla equidade en salud? Pan American Journal of Public Health, Washington, v. 11, n. 5-6, p. 302-309, 2002.

. Desigualdade reexaminada. Rio de Janeiro: Record; 2001. 301p.

SIQUEIRA-BATISTA, Rodrigo. Miséria. Rio de Janeiro: KroArts; 2005.

SOUZA, Elza M. de; GRUNDY, Emily. Promoção da saúde, epidemiologia social e capital social: inter-relações e perspectivas para a saúde pública. Cad. Saúde Pública. Rio de Janeiro, v. 20, n. 5, p. 1354-1360, 2004.

TEIXEIRA, Mirna B. Empoderamento de idosos em grupos direcionados à promoção da saúde. 105p. Dissertação (Mestrado em Saúde Pública) - Escola Nacional de Saúde Pública, Fundação Oswaldo Cruz, Rio de Janeiro, 2002.

TRAD, Leny A. B.; BASTOS, Ana C. S. O impacto sócio-cultural do Programa de Saúde da Família (PSF): uma proposta de avaliação. Cad. Saúde Pública. Rio de Janeiro, v. 14, n. 2, p. 429435, 1998.

WORLD HEALTH ORGANIZATION. Glossary of health promotion terms. Geneva: WHOS, 1998. Health promotion: a discussion document on the concept and principles of health promotion. Health Promot., n. 1, p. 73-78, 1984. 


\section{Notas}

* Este estudo faz parte da dissertação de mestrado intitulada Controle Social no Sistema Único de Saúde: Análise da Participação Social e do Empoderamento da População no Município de Teixeiras, MG, financiada pela FAPEMIG, EDT - Processo n. 075/05 - 2005.

${ }^{1}$ O termo "formar" traz implícito o ideário grego de Paideia, definida por Platão como "a essência de toda a verdadeira educação ou Paideia é a que dá ao homem o desejo e a ânsia de se tornar um cidadão perfeito e o ensina a mandar e a obedecer, tendo a justiça como fundamento" (JAEGER, 1995, p. 147). 
Democracy and empowerment in the context of promotion of health: possibilities and challenges presented to the Family Health Program The Family Health Program (FHP) is considered one of the main strategies for reorganization of the Brazilian Unified Health System, redirecting the model of attention to the health in Brazil, acting as a new standard which valorizes the actions towards the promotion of health, prevention of diseases and curative care. In the context of democracy in health, the promotion of health is highlighted as a process where the individuals are trained to have a greater control on their own health, recognizing the importance of the power and control on the health determiners; using strategies which aim to empower the individuals, increasing their participation on the modification of the relevant elements to the health. This article aims to achieve a critical reflection on the importance of the SFP for the promotion and stimulus to the empowerment/liberation of the population, glimpsing from them a more active participation in the decisionmaking in health.

> Key words: community involvement; health education; Family Health Program; health system. 